\title{
REVIEW
}

\section{Activation-induced cell death in B lymphocytes}

\author{
Donjerković Dubravka, David W Scott \\ Department of Immunology, Holland Laboratory for the Bio- \\ medical Sciences, American Red Cross, 15601 Crabbs Branch \\ Way, Rockville, MD, 20855. USA
}

\begin{abstract}
Upon encountering the antigen (Ag), the immune system can either develop a specific immune response or enter a specific state of unresponsiveness, tolerance. The response of $B$ cells to their specific Ag can be activation and proliferation, leading to the immune response, or anergy and activationinduced cell death (AICD), leading to tolerance. AICD in B lymphocytes is a highly regulated event initiated by crosslinking of the B cell receptor (BCR). BCR engagement initiates several signaling events such as activation of PLC $\gamma$, Ras, and PI3K, which generally speaking, lead to survival. However, in the absence of survival signals (CD40 or IL-4R engagement), BCR crosslinking can also promote apoptotic signal transduction pathways such as activation of effector caspases, expression of pro-apoptotic genes, and inhibition of pro-survival genes. The complex interplay between survival and death signals determines the B cell fate and, consequently, the immune response.
\end{abstract}

Key words: $B$ lymphocytes, activation-induced cell death, $B$ cell receptor.

\section{INTRODUCTION}

In order for the B cell to be activated and to proliferate, or to undergo AICD or

\footnotetext{
* Correspondence: Prof. David W. Scott

Tel: (301) 517-0355; Fax: (301) 517-0344; E-mail: scottd@usa.redcross.org
} 
B cell apoptosis

anergy, it has to be signaled via its BCR. During the course of development, the immature B cell is the first stage at which the B cell expresses functional membrane immunoglobulin $(\mathrm{mIg})$ that can recognize $\mathrm{Ag}$ and transmit signal. In general, crosslinking of mIgM results in apoptosis of immature B cells and in proliferation of mature B cells. There are four possible explanations for a negative response to Ag by immature B cells (reviewed in[1]): 1) developmentally regulated differences in Ig isotype expression; 2) lack of $\mathrm{T}$ cell help (co-stimulatory signal) in areas of hematopoiesis (such as bone marrow), or inability of immature B cells to receive a second signal from T cells; 3) negative autocrine factors secreted by BCR-stimulated immature B cells and/or lack of positive signals derived from mature B cells; and 4) intrinsic differences in the integration of signals generated and transduced by the BCR at the immature and mature stage of development (independent of isotype). Which of these models is closest to reality, or whether a combination of two or more is correct, is still a debate, and this area of research needs further experimental evidence that would explain why immature B cells are more sensitive to AICD. An enormous amount of data in this field comes from in vitro models for B cell tolerance using either human or murine B-lymphoma cells of immature phenotype. WEHI-231, CH31 and CH33 cells, for example, are prototypical of such immature murine B-lymphoma cells in which mIgM crosslinking results in G1 growth arrest[2],[3] and subsequent apoptosis[4],[5]. In this review, signal transduction pathways initiated by BCR crosslinking will be discussed. Additionally, the role of c-Myc oncoprotein, p27 Kip1 cyclin kinase inhibitor (CKI), and caspases in mIgM-mediated growth arrest and apoptosis of B cells and B-lymphoma cells, will be presented.

\section{BCR-mediated signal transduction pathway}

One of the first steps in the signal transduction pathway triggered by BCR crosslinking is activation of the Src family members (Fig 1 ). The src family of kinases (reviewed in[6]) consists of several non-receptor protein tyrosine kinases such as Blk, Fgr, Fyn, Hck, Lck, Lyn, Src, and Yes. In B lineage cells, several members of the Src family are noncovalently coupled to an activated membrane Ig receptor complex, including $\mathrm{p} 55^{B l k}, \mathrm{p} 59^{F y n}, \mathrm{p} 53 / \mathrm{p} 56^{L y n}$, and $\mathrm{p} 56^{L c k}$ (reviewed in[7]). Using the antisense oligodeoxynucleotide approach, Yao et al.[8] showed that Blk kinase is implicated in anti-IgM-mediated growth arrest and apoptosis in murine B-lymphoma cells (reviewed in[9]). The BCR is a multimeric complex consisting of the ligand binding mIgM and two $\operatorname{Ig} \alpha / \operatorname{Ig} \beta$ heterodimers (reviewed in[10]). The cytoplasmic portion of Ig heavy chain is very short, and cytoplasmic portions of $\operatorname{Ig} \alpha / \operatorname{Ig} \beta$ heterodimers are necessary for signal transduction. The cytoplasmic tails of $\operatorname{Ig} \alpha$ and $\operatorname{Ig} \beta$ contain a consensus sequence termed immunoreceptor tyrosine-based activation motif (ITAM) which is required for the signal transduction and for anti-IgM-mediated growth arrest and apoptosis[11]. Selective point mutations of either one of the two conserved tyrosine residues within 
ITAM (Y23 and Y34) completely abrogates the ability of this motif to mediate anti-IgMinduced death signal. Furthermore, chimeric receptors containing extracellular and transmembrane portions of CD8 and intracellular portion of either $\operatorname{Ig} \alpha$ or $\operatorname{Ig} \beta$ can transduce growth arrest and death signal when crosslinked with anti-CD8 Ab[12]. In normal B cells, the N-terminus of Lyn and Fyn can bind unphosphorylated Iga and phosphorylate the first tyrosine residue of the ITAM. Phosphorylation of these residues then results in increased binding of proteins with Src-homology domain (SH), such as Src family members and the adapter protein Shc (Fig 1).

Events downstream from the initial activation of Blk in anti-IgM signaling in murine B-lymphoma cells are still largely unknown. In normal B cells, after initial tyrosine kinase activation, the BCR signaling pathway diverges into several different signaling cascades (reviewed in[13]). Activation of Src family kinases leads to activation of three different molecules that serve as transducers of the signal, namely phospholipase $\mathrm{C} \gamma$ (PLC $\gamma$, Ras, and phosphatidylinositol-3 kinase (PI3K; see Fig 1).

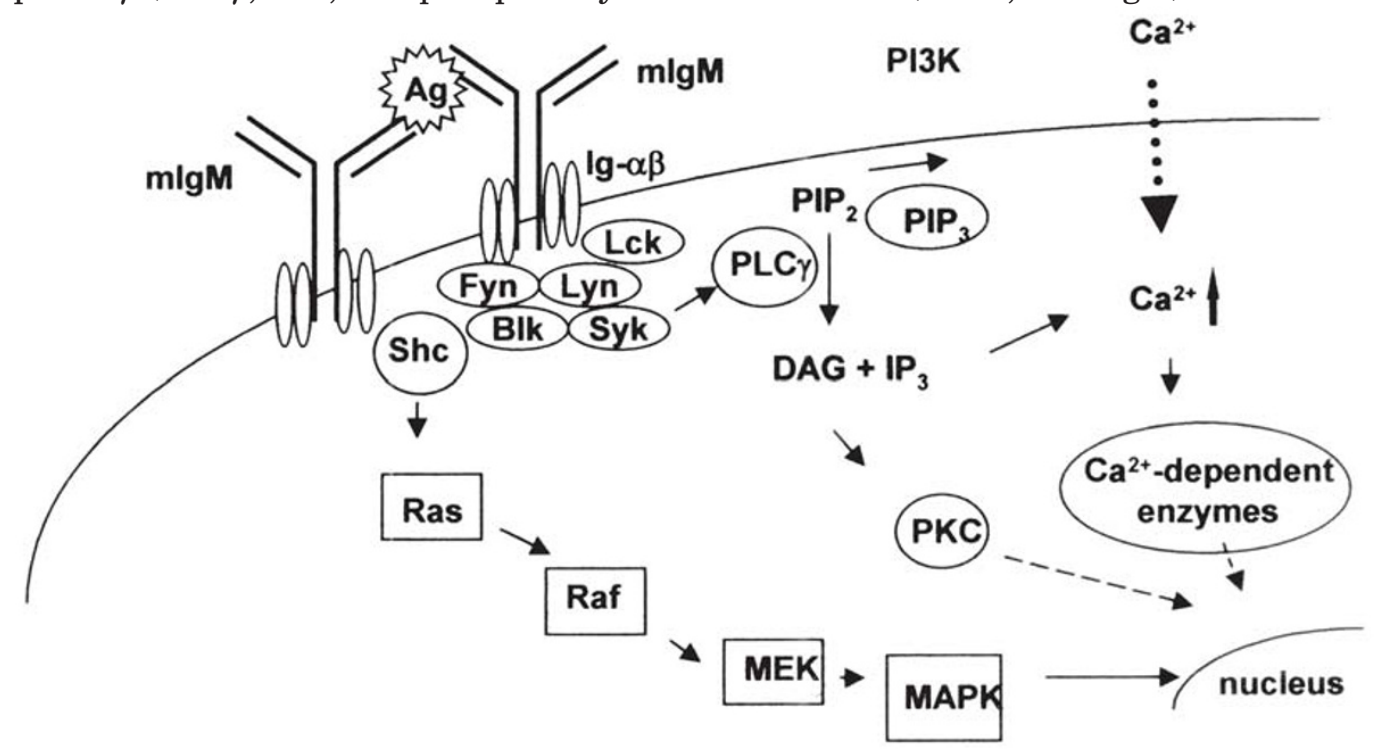

Fig 1. BCR-mediated signal transduction pathway

Crosslinking of mIgM activates Src family of non-receptor protein tyrosine kinases which phosphorylate conserved tyrosine residues in the ITAM motifs of $\operatorname{Ig} \alpha$ and $\operatorname{Ig} \beta$ cytoplasmic tails. This then leads to recruitment of Src homology domain containing proteins such as the adapter protein She, resulting in Ras-GDP to Ras-GTP conversion and activation of MAPK signal transduction pathway. Active MAPK translocates into nucleus and induces transcription. Activation of Src family kinases also leads to activation of PLC $\gamma$, an enzyme that breaks down PIP2 into the second messengers DAG and $\mathrm{IP}_{3}$. DAG mediates PKC activation, which in turn leads to activation of transcription factors AP-1 and NFkB. IP ${ }_{3}$ mediates an increase in free cytoplasmic calcium, which in turn activates calcium dependent enzymes such as calcineurin. Calcineurin is a phosphatase that dephosphorylates cytoplasmic component of nuclear factor of activated T cells (NFATc) transcription factor, thereby enabling its translocation into nucleus. Finally, activation of Src family kinases leads to PI3K activation, which in turn phosphorylates PIP $_{2}$ leading to PIP $_{3}$ second messenger. Downstream target of PI3K is PKB/Akt, which acts upon $\mathrm{p} 70^{\mathrm{S} 6 \mathrm{~K}}$, an enzyme implicated in mRNA translation. 
B cell apoptosis

\section{The role of PLCr in BCR signaling}

PLC $\gamma$ activation by phosphorylation results in phospholipid hydrolysis yielding inositol 1, 4, 5-trisphosphate $\left(\mathrm{IP}_{3}\right)$ and diacylglycerol (DAG), Fig 1 . These are the second messengers that mediate an increase of cytosolic free calcium (via activation of calcium release from the endoplasmic reticulum, as well as calcium influx) and activation of various protein kinase $\mathrm{C}$ (PKC; such as $\alpha, \beta$, and $\delta$ isozymes), respectively (Fig 1). Indeed, for DNA synthesis to occur and for B cells to proliferate upon BCR crosslinking, there must be a small, but sustained increase in cytoplasmic free calcium [14]. Furthermore, B cell stimulation via BCR crosslinking can be successfully mimicked using calcium ionophores (such as ionomycin) to increase cytoplasmic free calcium, in combination with phorbol esters (such as PMA) to activate PKC[15]. Calcium mobilization, in turn, leads to activation of calcium calmodulin regulated enzymes as well as activation of calcineurin, a calcium-dependent phosphatase. PKC activation, on the other hand, leads to activation of AP-1 and NFakB transcription factors.

Anti-IgM treatment of WEHI-231, CH31, CH33, and ECH408 cells also leads to a rapid increase in cytosolic free calcium, as a result of both mobilization from internal stores and influx via calcium channels[16],[17]. Ionomycin also augments anti-IgMinduced growth arrest and apoptosis[18]. Furthermore, in several immature B-lymphoma cells such as in murine B-lymphoma cells WEHI-231[19] or BKS-2[18], in Burkitt's lymphoma cells[20], and in the human B-lymphoma cell line, B104[21], elevation of cytosolic free calcium seems to be sufficient to induce growth inhibition and apoptosis. In agreement with this notion, immunosuppressant cyclosporin A (CsA) that inhibits calcineurin (reviewed in[22]), protects some of these B-lymphoma cells from calcium-induced, as well as from anti-IgM-induced growth arrest and apoptosis [23]. However, the role of immunosuppressants in immature B-lymphoma cells is still controversial since several other groups reported that CsA, FK506 and rapamycin actually induce growth arrest and apoptosis in WEHI-231 cells[24], [25]. Recently, we reported that in WEHI-231 cells, an increase in cytoplasmic free calcium is necessary for anti-IgM-mediated accumulation of CKI p27 ${ }^{K i p} 1$ [26]. As expected, CsA prevents antiIgM-induced $\mathrm{p} 27^{\mathrm{Kip}} 1 \mathrm{up}$-regulation in these cells.

The role of $\mathrm{PKC}$ in BCR signaling in immature B-lymphoma cells is still controversial. Activation of $\mathrm{PKC}$ is generally thought to result from the translocation of inactive cytosolic enzyme to activation sites in the cell membrane, which does not happen upon mIgM crosslinking of WEHI-231 cells[27]. In agreement with this, phorbol ester PMA was shown to rescue cells from ionomycin- or anti-IgM-induced growth arrest and apoptosis[16], [23],[28]. However, Kuwahara et al.[29] more recently reported that PKC (a and $\beta$ isozymes) can translocate from the cytosolic to the membrane compartment in WEHI-231 cells. In agreement with this, PMA was reported to actually induce growth arrest in WEHI-231 cells[30]. In conclusion, the role of PKC in BCR signaling in immature B-lymphoma cells is still controversial and needs further studies. 
Donjerkovic D and DW Scott

\section{The role of Ras in BCR signaling}

The second signal transduction cascade initiated by BCR crosslinking is mediated by Ras activation. src family kinase activation leads to recruitment of the $\mathrm{SH}$ domain containing proteins such as Shc. This, in turn, results in the conversion of inactive Ras-GDP into active Ras-GTP. Ras exerts its functions on nuclear events by stimulating a sequential phosphorylation cascade involving Raf-1, MAPK/Erk kinase (MEK) and mitogen-activated protein kinase (MAPK; Fig 1). The latter translocates into the nucleus to induce transcription. Crosslinking of $\mathrm{mIgM}$, as well as treatment with ionomycin, induces delayed but sustained activation of MAPK in human B-lymphoma cell line B104. CsA inhibits MAPK activation and can protect B lymphoma cell lines from anti-IgM- or ionomycin-induced apoptosis, suggesting that stimulation of MAPK might be required for the induction of apoptosis[21], although it remains possible that CsA effect is simply due to the inhibition of the calcium signal which is responsible for the death.

\section{The role of PI3K in BCR signaling}

PI3K (reviewed in [31]) has been implicated in BCR signaling (reviewed in[32]), see Fig 1. An $85 \mathrm{kDa}$ regulatory subunit of this kinase has SH3 and SH2 domains (reviewed in[33]) that enable it to associate with the BCR complex, thereby positioning the 110 $\mathrm{kDa}$ catalytic subunit near the membrane where it phosphorylates phosphatidylinositol 4, 5-bisphosphate $\left(\mathrm{PIP}_{2}\right)$ to the second messenger phosphatidylinositol 3, 4, 5trisphosphate PIP3 (Fig 1). One of the important downstream targets of PI3K is PKB/ Akt, a kinase that acts upon $\mathrm{p} 70^{\mathrm{S} 6 K}$. Another downstream target of PKB has more recently been reported, albeit in $\mathrm{T}$ cells[34]. These authors showed that IL-2-induced $\mathrm{T}$ cell proliferation is a result of pRb hyperphosphorylation. This, in turn, is a consequence of IL-2-induced p27 $7^{\text {Kip } 1}$ down-regulation and cyclin D3 (the most abundant D-type cyclin in $\mathrm{T}$ cells) up-regulation mediated via PI3/PKB pathway. IL-2-mediated $\mathrm{p} 27^{\text {Kip } 1}$ down-regulation is prevented by immunosuppressant rapamycin, an inhibitor of $\mathrm{p} 70^{\mathrm{S} 6 K}$ [35]. In anti-IgM-treated WEHI-231 cells, there is a sustained decrease in PIP3 levels bellow the baseline as early as $1 \mathrm{~h}$ after the treatment (Carey and Scott, in preparation). Anti-IgD treatment, on the other hand, also induces PI3K inactivation at the $1 \mathrm{~h}$ time point, but the PIP3 levels return to and remain at the baseline at 4-8 $\mathrm{h}$ after the treatment. Additionally, only anti-IgM, but not anti-IgD, induces sustained inactivation of $\mathrm{p} 70^{S 6 K}$, a downstream effector in PI3K signaling pathway. Finally, inhibition of PI3K pathway, using specific pharmacological inhibitors, induces G1 arrest and apoptosis, enhances anti-IgM-induced apoptosis, and converts anti-IgD into a death signal (Carey and Scott, in preparation). In conclusion, there is a correlation between BCR-mediated inactivation of PI3K/p70 ${ }^{S 6 K}$ pathway and BCR-mediated apoptosis in immature murine B-lymphoma cells. 
B cell apoptosis

\section{The role of c-Myc in BCR-mediated G1 arrest and apoptosis}

Mature B cells express low baseline levels of c-Myc. mIgM crosslinking of mature, resting $\mathrm{B}$ cells induces evanescent c-Myc up-regulation and cells enter the cell cycle [36]. However, extensive crosslinking of $\mathrm{mIgM}$ or $\mathrm{mIgD}$ can also lead to apoptosis of mature B cells, unless T cell help is provided either by IL-4 or by CD40L signaling[37]. Furthermore, anti-IgM-induced apoptosis of mature B cells can be prevented by c-myc antisense oligodeoxynucleotides, which prevent an anti-IgM-induced increase in c-Myc [36]. Together, these data suggest that BCR-induced apoptosis of mature B cells may be due to an overexpression of c-Myc in the absence of co-stimulatory signals provided by $\mathrm{T}$ helper cells.

In immature B-lymphoma cells, the situation is different. mIgM crosslinking in unsynchronized murine B-lymphoma cells (such as WEHI-231, CH31, and ECH408), leads to a transient increase in c-myc mRNA and protein within one to two hours, and a decrease to much below the baseline level at four to eight hours[38-40]. Human Burkitt's lymphoma cells also down-regulate c-Myc upon mIgM crosslinking[41]. IgD crosslinking, on the other hand, also leads to a transient increase in c-Myc, but the levels of mRNA and protein never drop below the baseline levels ([39]; Liu et al., in preparation).

Extensive evidence from Sonenshein and colleagues (reviewed in[42],[43]), as well as from Scott and coworkers (reviewed in[44]), suggest that down-regulation of c-Myc is necessary for anti-IgM-induced apoptosis. The strongest experimental evidence that supports this notion is that overexpression of exogenous c-Myc protects WEHI-231 cells from anti-IgM-induced apoptosis[45] and that stabilization of c-Myc levels by antisense c-myc oligodeoxynucleotides rescues WEHI-231 and CH31 cells from antiIgM-induced apoptosis[40]. Conversely, inhibition of c-Myc expression using a serine/ threonine protease inhibitor TPCK (N-tosyl-L-phenylalanine chloromethyl ketone) induces apoptosis in WEHI-231 cells[45]. Additionally, down-regulation of c-Myc (using a pharmacological inhibitor of c-Myc, FR901228), together with an increase in cytoplasmic free calcium results in accumulation of p27 ${ }^{\text {Kip } 1}$, G1 arrest, and apoptosis in WEHI-231 and ECH408 cells.

There is one NFkB binding site in c-myc promoter and one upstream of the promoter (reviewed in[46]), and c-myc transcription in WEHI-231 cells seems to be regulated by $\mathrm{NFkB}$ [47]. Consequently, inhibition of $\mathrm{NF} \kappa \mathrm{B}$ using the drug TPCK, (a serine/ threonine protease inhibitor that inhibits $\mathrm{I} \kappa \mathrm{B}$ degradation, thereby inactivating $\mathrm{NF} \kappa \mathrm{B}$ ), or microinjection of IkB induces apoptosis in WEHI-231 cells via c-Myc down-regulation[48]. NF $\kappa \mathrm{B}$ (reviewed in[49]) binds to DNA as a dimer that can be composed of the following subunits: RelA (p65), RelB, c-Rel, p50, and p52. In WEHI-231 cells, the major $\mathrm{NF} \kappa \mathrm{B}$ species is p50/c-Rel heterodimer, but minor amounts of p50/RelA are also present.

In conclusion, resting, mature B cells express low basal levels of c-Myc and upregulate it upon BCR stimulation, leading to either proliferation (in the presence of a 
co-stimulatory signal) or apoptosis (in the absence of $\mathrm{T}$ cell help). Immature, Blymphoma cells, on the other hand, express high levels of c-Myc and profoundly downregulate it upon stimulation, leading to growth arrest and apoptosis. Very recently however, Tsubata and colleagues[50] reported that inducible over-expression of c-Myc results in apoptosis of WEHI-231 cells, suggesting that either profound down-regulation, or over-expression of c-myc oncogene, is lethal for these cells.

\section{The role of $T$ cell help in BCR-mediated G1 arrest and apoptosis}

For the sustained proliferation upon the engagement of the BCR, resting, mature, splenic B cells need a second co-stimulatory signal that is provided by $\mathrm{T}$ helper cells in vivo, and can be provided in vitro by co-culturing cells with IL-4 or with CD40L (or anti-CD40 Ab, see Fig 2). In the case of immature murine B-lymphoma cells, growth arrest and cell death induced via BCR engagement can be prevented by either IL-4 or CD40L. Addition of recombinant IL-4 in culture[51], or co-culture with activated Th2 clone that produces IL-4[52], rescues WEHI-231, CH33, and CH31 cells from anti-IgMinduced growth arrest (reviewed in[53]). Engagement of CD40 expressed on the surface of B cells, with its ligand (CD40L) expressed on the surface of T cells (Fig 2), protects

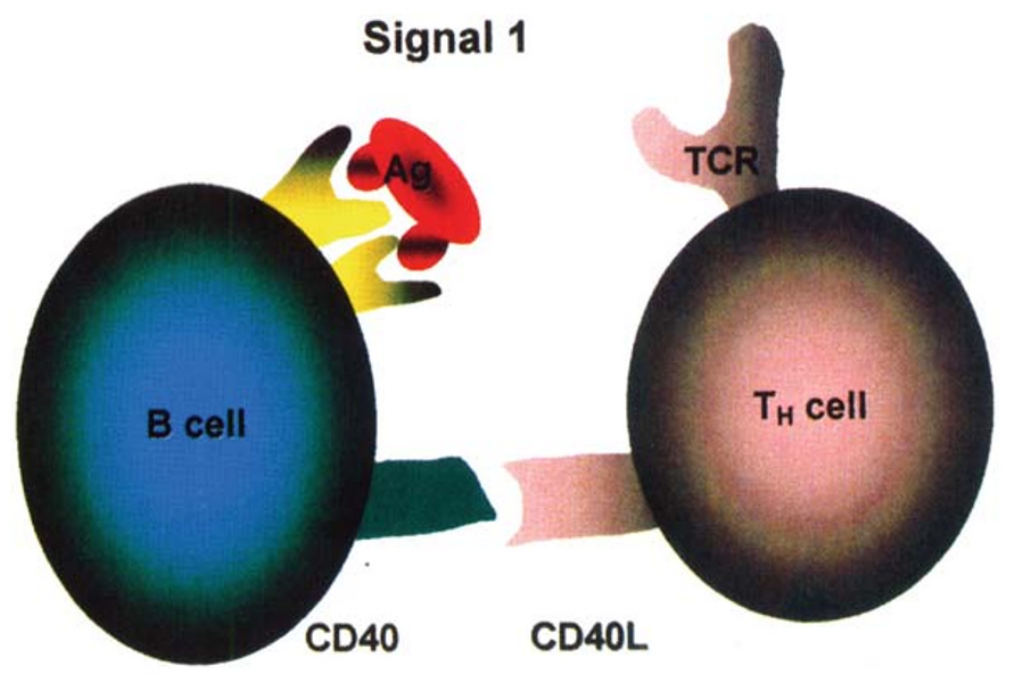

Signal 2

Fig 2.The two signal model for B cell activation Activation of resting B cells requires two signals. The first signal is generated by antigen-mediated BCR crosslinking and the second is provided by T cell help, via CD40/CD40L engagement. Signal one in the absence of signal two leads to abortive activation, anergy, or deletion, resulting in tolerance to the activation antigen. In the presence of signal two, signal one leads to B cell activation, proliferation and/or differentiation. 
B cell apoptosis

immature human[54] as well as murine[55] B-lymphoma cells from anti-IgM-induced apoptosis and growth arrest. A 17 amino acid domain within the cytoplasmic portion of CD40L called TIM (TRAF family member interacting motif) that binds TNFR associated factor (TRAF) family members is necessary and sufficient for the protective effect of CD40L[56]. CD40L prevents anti-IgM-induced c-Myc down-regulation via maintaining $\mathrm{NF} \kappa \mathrm{B}$ activity in WEHI-231 cells[57]. It seems that CD40L maintains $\mathrm{NF} \kappa \mathrm{B}$ activity by inducing a sustained decrease in IkBa and a transient decrease in $\mathrm{IkB} \beta$. As expected, microinjection of IkBa into the nuclei of WEHI-231 cells ablates protection mediated by CD40L[58].

An important effect of signaling via CD40/CD40L engagement on WEHI-231 cells is maintenance of high c-Myc levels via maintaining $\mathrm{NF} \kappa \mathrm{B}$ activity. In addition, signaling by CD40 has another important effect, which is induction of anti-apoptotic Bcl-xL protein[59-61]. Indeed, overexpression of Bcl-xL rescues WEHI-231 cells from antiIgM-mediated apoptosis[62], while having no effect on G1 growth arrest. These results suggest that the Bcl- $\mathrm{x}_{\mathrm{L}}$-inhibitable event is either downstream of growth arrest, or on a separate signal transduction pathway. Bcl-2 overexpressing cells are not only resistant to apoptosis mediated by BCR crosslinking, but also to apoptosis following serum deprivation, $\gamma$-irradiation, exposure to ceramides or compounds that increase the intracellular level of oxidants[63]. Furthermore, immunosuppressants (such as rapamycin, FK506, and CsA) have been shown to induce growth arrest and apoptosis in immature B-lymphoma cells[24],[25] and Bcl-xL protects WEHI-231 cells from apoptosis induced by these compounds. Again, Bcl-xL has no effect on the G1 arrest mediated by these immunosuppressants[24].

\section{The role of cell cycle proteins in BCR-mediated G1 arrest and apoptosis}

Mature, resting B cells express very low basal levels of Cdk2 and Cdk4 and high levels of CKI p27 $7^{\text {Kip } 1}$. Upon complete stimulation with PMA and ionomycin, Cdk2, Cdk4, cyclin D2, and cyclin E protein levels increase[64]. Interestingly, complete stimulation of mature B cells (BCR crosslinking and CD40 engagement) also leads to CKI p21Cip1 accumulation[65]. If BCR crosslinking and IL-4 are used as a complete stimulus, in addition to $\mathrm{Cdk} 2$, Cdk4, cyclin D2, cyclin $\mathrm{E}$, and $\mathrm{p} 21^{\mathrm{Cip} 1}$, mature $\mathrm{B}$ cells also increase expression of cyclin D3, cyclin A, and cyclin B as well as Cdk6, Cdc2 and CKI p19 ${ }^{I N K 4 D}$ [66]. Furthermore, stimulation of resting B cells with anti-IgM and IL-4 causes very rapid down-regulation of $\mathrm{p} 27^{\mathrm{Kip} 1}$. However, this down-regulation is only transient, but can become permanent if CD40L is also added to the culture. As expected, addition of CD40L in the culture results in long-term B cell proliferation[66].

Crosslinking of BCR on the surface of immature B cells results in apoptosis as well as in growth arrest in late G1 phase of the cell cycle. Furthermore, cells are sensitive to anti-IgM treatment only when in early G1 phase[3]. As one would predict, in these 
growth arrested cells (such as anti-IgM-treated WEHI-231 or CH31 cells), pRb is in its active, growth suppressive form, i.e. it is hypophosphorylated[67]. Additionally, BCR crosslinking also leads to hypophosphorylation of another $\mathrm{pRb}$ family member, $\mathrm{p} 130$ [68]. The appearance of the hypophosphorylated form of pRb family members correlates with inhibition of Cdk2 kinase activity. Since Cdk2/cyclin complexes are responsible for phosphorylation of $\mathrm{pRb}$ family members at $\mathrm{G} 1$ to $\mathrm{S}$ transition, inactivation of Cdk2 can explain why these cells are arrested in late G1 phase[69],[70]. However, anti-IgM-mediated reduction in Cdk2 kinase activity is not the result of decreased expression of Cdk2, cyclin A, or cyclin $\mathrm{E}$ since the levels of these proteins do not change upon the treatment[70]. It also does not appear to involve cyclin dependent kinase activating kinase (CAK) whose activity is not affected by BCR crosslinking[71]. How does anti-IgM treatment decrease Cdk2 activity? Immature murine B-lymphoma cells are proliferating cells and, as expected, have very low basal levels of CKI p27 Kip1. Inactivation of $\mathrm{Cdk} 2$ by anti-IgM correlates with an increased total amount of $\mathrm{p} 27^{\text {Kip } 1}$ in the cells, and more importantly, it correlates with the amount of $\mathrm{p} 27^{\text {Kip } 1}$ present in cyclin $\mathrm{A}[70]$ and $\mathrm{Cdk} 2[71]$ complexes. Furthermore, the amount of $\mathrm{p} 27^{\mathrm{Kip} 1}$ in cyclin A complexes correlates with the percentage of the cells in G1 phase upon BCR crosslinking. Finally, CD40L, which rescues WEHI-231 cells from anti-IgM-induced apoptosis and growth arrest, also prevents $\mathrm{p} 27^{\text {Kip } 1}$ accumulation upon BCR crosslinking[71], or upon co-treatment with ionomycin and FR901228[26]. One group reported that BCR crosslinking in WEHI-231 cells results in decreased protein levels of early G1 kinases Cdk4 and Cdk6 which can be prevented by CD40/CD40L engagement[60], but this has not been reproduced[70]. Finally, Sonenshein and coworkers reported that anti-IgM treatment increases p53 expression, and consequently $\mathrm{p} 21^{\text {Cip } 1}$ expression ( $\mathrm{p} 21^{\text {Cip } 1}$ is under positive transcriptional control of p53)[72].

In conclusion, while resting, mature $B$ cells express high levels of $\mathrm{p} 27^{\text {Kip } 1}$ and profoundly down-regulate it upon stimulation which leads to proliferation, in immature B-lymphoma cells the situation is the opposite. These cells are continuously proliferating and express very low basal levels of $\mathrm{p} 27^{\text {Kip } 1}$, which is profoundly up-regulated upon stimulation that leads to G1 arrest and apoptosis.

\section{The role of caspases in BCR-mediated G1 arrest and apoptosis}

Caspases, a family of cysteine proteases, are crucial executors of apoptosis in mammalian cells. Indeed, as one might predict, BCR-mediated apoptosis also involves activation of caspases and can be inhibited by caspase inhibitors. For example, a broad spectrum inhibitor carbobenzoxy-Val-Ala-Asp-fluoromethyl ketone (Z-VAD-FMK) inhibits anti-IgM-induced apoptosis in WEHI-231[26],[73] and in CH31 [74] immature Blymphoma cells. However, caspase inhibitors have no effect on anti-BCR-induced inhibition of Cdk2 kinase activity and induction of G1 growth arrest[73], nor on anti-BCRinduced c-Myc down-regulation and $\mathrm{p} 27^{\text {Kip } 1}$ accumulation[26]. Together, these data 
B cell apoptosis

suggest that anti-IgM-induced down-regulation of c-Myc, accumulation of $\mathrm{p} 27^{\text {Kip } 1}$, and growth arrest are either upstream or on a separate pathway(s) from caspase activation. Which caspases exactly are activated by BCR crosslinking? Anti-IgM treatment of WEHI231 cells or extensive mIgM crosslinking in mature B cells leads to caspase 7 activation while caspase 2 and caspase 3 are not activated[73]. In CH31 cells, treated with anti-IgM, caspase 3-like activity is observed as shown by poly (ADP-ribose) polymerase (PARP) cleavage (PARP is a substrate of caspase 3 subfamily of caspases, i. e. caspase 2, 3, and 7), [74].

Finally, even though crosslinking of BCR in immature B cells, as well as in mature B cells (if the T cell help is not provided, or if crosslinking is extensive), can lead to apoptosis, it can also protect splenic cells[75] and A20 murine B-lymphoma cells[76] from CD95-induced apoptosis (reviewed in[77]). CD95 signaling activates caspase 8 in A20 cells and induces apoptosis. Both of these events can be prevented by BCR (mIgG in this case) crosslinking[76]. In this experimental system CD95 ligation also triggers Bcl-2 and Bcl- $\mathrm{x}_{\mathrm{L}}$ down-regulation, which is prevented by BCR crosslinking as well as by caspase inhibitor acetyl-Tyr-Val-Ala-Asp-chloromethyl ketone (YVAD-CMK).

\section{CONCLUSION}

AICD is an essential property of the lymphocytes and plays an important role in the development of the immune repertoire, as well as in the regulation of the immune response. In recent years, we learned a lot about programmed cell death in mammalian cells, and this knowledge greatly enhanced our understanding of the molecular mechanisms of AICD in both B and T cells. Some signaling events that lead to AICD in lymphocytes seem to be universal (such as activation of effector caspases), while the others are specific for lymphocyte lineages (such as engagement of BCR or T cell receptor). Further elucidation of the molecular events that determine whether a B cell will proliferate, survive in growth arrested state (anergy), or die via AICD will provide a potential for a novel therapeutic approaches in the treatment of immune disorders where AICD is desirable (auto-immunity), as well as in disorders where AICD is detrimental (immuno-deficiency).

\section{ACKNOWLEDGEMENTS}

This work was supported by USPHS grant CA55644.

\section{REFERENCE}

[1] Monroe JG. Tolerance sensitivity of immature-stage B cells: can developmentally regulated B cell antigen receptor (BCR) signal transduction play a role? J Immunol 1996; 156:2657-60.

[2] Pennell CA, Scott DW. Lymphoma models for B cell activation and tolerance. IV. Growth inhibition by anti-Ig of CH31 and CH33 B lymphoma cells. Eur J Immunol 1986; 16:1577-81.

[3] Scott DW, Livnat D, Pennell CA et al. Lymphoma models for B cell activation and tolerance. III. Cell cycle dependence for negative signalling of WEHI-231 B lymphoma cells by anti-mu. J Exp Med 1986; 164:156-64. 


\section{Donjerkovic D and DW Scott}

[4] Benhamou LE, Cazenave PA, Sarthou P. Anti- immunoglobulins induce death by apoptosis in WEHI231 B lymphoma cells. Eur J Immunol 1990; 20:1405-7.

[5] Hasbold J, Klaus GG. Anti-immunoglobulin antibodies induce apoptosis in immature B cell lymphomas. Eur J Immunol 1990; 20:1685-90.

[6] Muthuswamy SK, Muller WJ. Activation of the Src family of tyrosine kinases in mammary tumorigenesis. Adv Cancer Res 1994; 64:111-23.

[7] Vihinen M, Smith CI. Structural aspects of signal transduction in B-cells. Crit Rev Immunol 1996; 16:251-75.

[8] Yao XR, Scott DW. Antisense oligodeoxynucleotides to the Blk tyrosine kinase prevent anti-muchain-mediated growth inhibition and apoptosis in a B-cell lymphoma. Proc Natl Acad Sci USA 1993; 90: 7946-50.

[9] Yao XR, Scott DW. Expression of protein tyrosine kinases in the Ig complex of anti-mu-sensitive and anti-mu-resistant B-cell lymphomas: role of the p55Blk kinase in signaling growth arrest and apoptosis. Immunol Rev 1993; 132:163-86.

[10] Reth M. The B-cell antigen receptor complex and co-receptors. Immunol Today 1995; 16:310-3.

[11] Yao XR, Flaswinkel H, Reth M et al. Immunoreceptor tyrosine-based activation motif is required to signal pathways of receptor-mediated growth arrest and apoptosis in murine B lymphoma cells. J Immunol 1995; 155:652-61.

[12] Yao XR, Scott DW. Independent signaling for growth arrest and apoptosis by Ig alpha and Ig beta subunits of the B-cell antigen eptor complex. Ann N Y Acad Sci 1995; 766:96-8

[13] Berridge MJ. Lymphocyte activation in health and disease. Crit Rev Immunol 1997; 17:155-78.

[14] Yamada H, June CH, Finkelman F et al. Persistent calcium elevation correlates with the induction of surface immunoglobulin-mediated B cell DNA synthesis. J Exp Med 1993; 177:1613-21.

[15] Rothstein TL, Baeker TR, Miller RA et al. Stimulation of murine B cells by the combination of calcium ionophore plus phorbol ester. Cell Immunol 1986; 102:364-73.

[16] Scott DW, Livnat D, Whitin J et al. Lymphoma models for B cell activation and tolerance. V. AntiIg mediated growth inhibition is reversed by phorbol myristate acetate but does not involve changes in cytosolic free calcium. J Mol Cell Immunol 1987; 3:109-20.

[17] Gold MR, DeFranco AL. Phorbol esters and dioctanoylglycerol block anti-IgM-stimulated phosphoinositide hydrolysis in the murine B cell lymphoma WEHI-231. J Immunol 1987; 138:86876.

[18] Muthukkumar S, Udhayakumar V, Bondada S. Elevation of cytosolic calcium is sufficient to induce growth inhibition in a B cell lymphoma. Eur J Immunol 1993; 23:2419-26.

[19] Genestier L, Dearden-Badet MT, Bonnefoy-Berard N et al. Cyclosporin A and FK506 inhibit activation-induced cell death in the murine WEHI-231 B cell line. Cell Immunol 1994; 155:283-91.

[20] Bonnefoy-Berard N, Genestier L, Flacher M et al. The phosphoprotein phosphatase calcineurin controls calcium-dependent apoptosis in B cell lines. Eur J Immunol 1994; 24:325-9.

[21] Graves JD, Draves KE, Craxton A et al. Involvement of stress-activated protein kinase and p38 mitogen-activated protein kinase in mIgM-induced apoptosis of human B lymphocytes. Proc Natl Acad Sci USA 1996; 93:13814-8.

[22] Sigal NH, Dumont FJ. Cyclosporin A, FK-506, and rapamycin: pharmacologic probes of lymphocyte signal transduction. Annu Rev Immunol 1992; 10:519-60.

[23] Higashigawa M, Komada Y, Shimono Y et al. FK506 inhibits anti-IgM antibody-induced apoptosis and $17 \mathrm{kD}$ endonuclease activity in the human B-cell line, MBC-1, established from Burkitt' $\mathrm{s}$ lymphoma. Br J Haematol 1997; 99:908-13.

[24] Gottschalk AR, Boise LH, Thompson CB et al. Identification of immunosuppressant-induced apoptosis in a murine B-cell line and its prevention by bcl-x but not bcl-2. Proc Natl Acad Sci USA 1994; 91:7350-4.

[25] Muthukkumar S, Ramesh TM, Bondada S. Rapamycin, a potent immunosuppressive drug, causes 


\section{B cell apoptosis}

programmed cell death in B lymphoma cells. Transplantation 1995; 60:264-70.

[26] Donjerkovic D, Zhang L, Scott DW. Regulation of p27Kip1 accumulation in murine B-lymphoma cells: role of c-Myc and calcium In Process Citation]. Cell Growth Differ 1999; 10:695-704.

[27] Sarthou P, Henry-Toulme N, Cazenave PA. Membrane IgM cross-linking is not coupled to protein kinase C translocation in WEHI-231 B lymphoma cells. Eur J Immunol 1989; 19:1247-52.

[28] Warner GL, Scott DW. Lymphoma models for B-cell activation and tolerance. VII. Pathways in anti-Ig-mediated growth inhibition and its reversal. Cell Immunol 1988; 115:195-203.

[29] Kuwahara K, Kawai T, Mitsuyoshi S et al. Cross-linking of B cell antigen receptor-related structure of pre-B cell lines induces tyrosine phosphorylation of p85 and p110 subunits and activation of phosphatidylinositol 3-kinase. Int Immunol 1996; 8:1273-85.

[30] Maheswaran S, McCormack JE, Sonenshein GE. Changes in phosphorylation of myc oncogene and $\mathrm{RB}$ antioncogene protein products during growth arrest of the murine lymphoma WEHI 231 cell line. Oncogene 1991; 6:1965-71.

[31] Fruman DA, Meyers RE, Cantley LC. Phosphoinositide kinases. Annu Rev Biochem 1998; 67:481507.

[32] Campbell KS. Signal transduction from the B cell antigen-receptor. Curr Opin Immunol 1999; 11: 256-64.

[33] Pawson T. SH2 and SH3 domains in signal transduction. Adv Cancer Res 1994; 64:87-110.

[34] Brennan P, Babbage JW, Burgering BM et al. Phosphatidylinositol 3-kinase couples the interleukin2 receptor to the cell cycle regulator E2F. Immunity 1997; 7:679-89.

[35] Nourse J, Firpo E, Flanagan WM et al. Interleukin-2-mediated elimination of the p27Kip1 cyclindependent kinase inhibitor prevented by rapamycin. Nature 1994; 372:570-3.

[36] Scott DW, Lamers M, Kohler G et al. Role of c-myc and CD45 in spontaneous and anti-receptorinduced apoptosis in adult murine B cells. Int Immunol 1996; 8:1375-85.

[37] Parry SL, Hasbold J, Holman M et al. Hypercross-linking surface IgM or IgD receptors on mature B cells induces apoptosis that is reversed by costimulation with IL-4 and anti-CD40. J Immunol 1994; 152:2821-9.

[38] McCormack JE, Pepe VH, Kent RB et al. Specific regulation of c-myc oncogene expression in a murine B-cell lymphoma. Proc Natl Acad Sci USA 1984; 81:5546-50.

[39] Tisch R, Roifman CM, Hozumi N. Functional differences between immunoglobulins M and D expressed on the surface of an immature B-cell line. Proc Natl Acad Sci USA 1988; 85:6914-8.

[40] Fischer G, Kent SC, Joseph L et al. Lymphoma models for B cell activation and tolerance. X. Antimu-mediated growth arrest and apoptosis of murine B cell lymphomas is prevented by the stabilization of myc. J Exp Med 1994; 179:221-8.

[41] Kaptein JS, Lin CKE, Wang CL et al. Anti-IgM-mediated regulation of c-myc and its possible relationship to apoptosis. J Biol Chem 1996; 271:18875-84.

[42] Wu M, Yang W, Bellas RE et al. c-myc promotes survival of WEHI 231 B lymphoma cells from apoptosis. Curr Top Microbiol Immunol 1997; 224:91-101.

[43] Sonenshein GE. Down-modulation of c-myc expression induces apoptosis of B lymphocyte models of tolerance via clonal deletion. J Immunol 1997; 158:1994-7.

[44] Scott DW, Donjerkovic D, Maddox B et al. Role of c-myc and p27 in anti-IgM induced B-lymphoma apoptosis. Curr Top Microbiol Immunol 1997; 224:103-12.

[45] Wu M, Arsura M, Bellas RE et al. Inhibition of c-myc expression induces apoptosis of WEHI 231 murine B cells. Mol Cell Biol 1996; 16:5015-25.

[46] Potter M, Marcu KB. The c-myc story: where we've been, where we seem to be going. Curr Top Microbiol Immunol 1997; 224:1-17.

[47] Lee H, Arsura M, Wu M et al. Role of Rel-related factors in control of c-myc gene transcription in receptor-mediated apoptosis of the murine B cell WEHI 231 line. J Exp Med 1995; 181:1169-77.

[48] Wu M, Lee H, Bellas RE et al. Inhibition of NF-kappaB/Rel induces apoptosis of murine B cells. 


\section{Donjerkovic D and DW Scott}

Embo J 1996; 15:4682-90.

[49] Baeuerle PA. IkappaB-NF-kappaB structures: at the interface of inflammation control [comment]. Cell 1998; 95:729-31.

[50] Hagiyama H, Adachi T, Yoshida T et al. Signaling through the antigen receptor of B lymphocytes activates a p53-independent pathway of c-Myc-induced apoptosis. Oncogene 1999; 18:4091-8.

[51] Scott DW, O'Garra A, Warren D et al. Lymphoma models for B cell activation and tolerance. VI. Reversal of anti-Ig-mediated negative signaling by T cell-derived lymphokines. J Immunol 1987; 139: 3924-9.

[52] Ales-Martinez JE, Silver L, LoCascio N et al. Lymphoma models for B-cell activation and tolerance. IX. Efficient reversal of anti-Ig-mediated growth inhibition by an activated TH2 clone. Cell Immunol 1991; 135:402-9.

[53] Ales-Martinez JE, Cuende E, Gaur A et al. Prevention of B cell clonal deletion and anergy by activated T cells and their lymphokines. Semin Immunol 1992; 4:195-202.

[54] Wang H, Grand RJ, Milner AE et al. Repression of apoptosis in human B-lymphoma cells by CD40ligand and Bcl-2: relationship to the cell-cycle and role of the retinoblastoma protein. Oncogene 1996; 13:373-9.

[55] Tsubata T, Wu J, Honjo T. B-cell apoptosis induced by antigen receptor crosslinking is blocked by a T-cell signal through CD40. Nature 1993; 364:645-8.

[56] Hornung M, Lindemann D, Kraus C et al. The CD40 TRAF family member interacting motif carries the information to rescue WEHI 231 cells from anti-IGM-induced growth arrest [published erratum appears in Eur J Immunol 1999 May; 29(5):1751]. Eur J Immunol 1998; 28:3812-23.

[57] Schauer SL, Wang Z, Sonenshein GE et al. Maintenance of nuclear factor-kappa B/Rel and c-myc expression during CD40 ligand rescue of WEHI 231 early B cells from receptor-mediated apoptosis through modulation of I kappa B proteins. J Immunol 1996; 157:81-6.

[58] Schauer SL, Bellas RE, Sonenshein GE. Dominant signals leading to inhibitor kappaB protein degradation mediate CD40 ligand rescue of WEHI 231 immature B cells from receptor-mediated apoptosis. J Immunol 1998; 160:4398-405.

[59] Wang Z, Karras JG, Howard RG et al. Induction of bcl-x by CD40 engagement rescues sIg-induced apoptosis in murine B cells. J Immunol 1995; 155:3722-5.

[60] Ishida T, Kobayashi N, Tojo T et al. CD40 signaling-mediated induction of Bcl-XL, Cdk4, and Cdk6. Implication of their cooperation in selective B cell growth. J Immunol 1995; 155:5527-35.

[61] Choi MS, Boise LH, Gottschalk AR et al. The role of bcl-XL in CD40-mediated rescue from antimu-induced apoptosis in WEHI-231 B lymphoma cells. Eur J Immunol 1995; 25:1352-7.

[62] Merino R, Grillot DA, Simonian PL et al. Modulation of anti-IgM-induced B cell apoptosis by BclxL and CD40 in WEHI-231 cells. Dissociation from cell cycle arrest and dependence on the avidity of the antibody-IgM receptor interaction. J Immunol 1995; 155:3830-8.

[63] Fang W, Rivard JJ, Ganser JA et al. Bcl-xL rescues WEHI 231 B lymphocytes from oxidantmediated death following diverse apoptotic stimuli. J Immunol 1995; 155:66-75.

[64] Reid S, Snow EC. The regulated expression of cell cycle-related proteins as B-lymphocytes enter and progress through the G1 cell cycle stage following delivery of complete versus partial activation stimuli. Mol Immunol 1996; 33:1139-51.

[65] Mullins MW, Pittner BT, Snow EC. CD40-mediated induction of p21 accumulation in resting and cycling B cells. Mol Immunol 1998; 35:567-80.

[66] Solvason N, Wu WW, Kabra N et al. Induction of cell cycle regulatory proteins in anti-immunoglobulin-stimulated mature B lymphocytes. J Exp Med 1996; 184:407-17.

[67] Warner GL, Ludlow JW, Nelson DA et al. Anti-immunoglobulin treatment of murine B-cell lymphomas induces active transforming growth factor beta but pRB hypophosphorylation is transforming growth factor beta independent. Cell Growth Differ 1992; 3:175-81.

[68] Lam EW, Choi MS, van der Sman J et al. Modulation of E2F activity via signaling through surface 


\section{B cell apoptosis}

IgM and CD40 receptors in WEHI-231 B lymphoma cells. J Biol Chem 1998; 273:10051-7.

[69] Joseph LF, Ezhevsky S, Scott DW. Lymphoma models for B-cell activation and tolerance: antiimmunoglobulin $\mathrm{M}$ treatment induces growth arrest by preventing the formation of an active kinase complex which phosphorylates retinoblastoma gene product in G1. Cell Growth Differ $1995 ; 6: 51-7$.

[70] Ezhevsky SA, Toyoshima H, Hunter T et al. Role of cyclin A and p27 in anti-IgM induced G1 growth arrest of murine B-cell lymphomas. Mol Biol Cell 1996; 7:553-64.

[71] Han H, Nomura T, Honjo T et al. Differential modulation of cyclin-dependent kinase inhibitor p27Kip1 by negative signaling via the antigen receptor of B cells and positive signaling via CD40. Eur J Immunol 1996; 26:2425-32.

[72] Wu M, Bellas RE, Shen J et al. Roles of the tumor suppressor p53 and the cyclin-dependent kinase inhibitor p21WAF1/CIP1 in receptor-mediated apoptosis of WEHI 231 B lymphoma cells. J Exp Med 1998; 187:1671-9 rec.

[73] Bras A, Ruiz-Vela A, Gonzalez de Buitrago G et al. Caspase activation by BCR cross-linking in immature B cells: differential effects on growth arrest and apoptosis. Faseb J 1999; 13:931-44.

[74] Andjelic S, Liou HC. Antigen receptor-induced B lymphocyte apoptosis mediated via a protease of the caspase family. Eur J Immunol 1998; 28:570-81.

[75] Rothstein TL, Wang JK, Panka DJ et al. Protection against Fas-dependent Th1-mediated apoptosis by antigen receptor engagement in B cells. Nature 1995; 374:163-5.

[76] Bras A, Martinez AC, Baixeras E. B cell receptor cross-linking prevents Fas-induced cell death by inactivating the IL- 1 beta-converting enzyme protease and regulating Bcl-2/Bcl-x expression. J Immunol 1997; 159:3168-77.

[77] Francis DA, Sen R, Rothstein TL. Receptor-specific regulation of NF-kappa B, c-Myc and Fasmediated apoptosis in primary B cells. Curr Top Microbiol Immunol 1997; 224:83-90. 